Www.jmscr.igmpublication.org

Index Copernicus Value: 79.54

ISSN (e)-2347-176x ISSN (p) 2455-0450

crossrefDOI: https://dx.doi.org/10.18535/jmscr/v7i2.172

Journal Of Medical Science And Clinical Research

IGM Publication

An Official Publication of IGM Publication

\title{
Foramen Magnum Decompression versus Foramen Magnum Decompression with Lax Duraplasty in Chiari-I Malformation- A Comparative Study
}

Authors

\author{
Dr S. Raj Kumar M.Ch., Dr P. Pallavan. M.Ch Neurosurgery Post Graduate \\ Prof. M. M. Sankar M.Ch., Dr R. Saravana Santhosh Kumar M.Ch \\ Government Stanley Medical College, Chennai, Tamilnadu, India
}

\begin{abstract}
Background: Despite progress in the understanding of the causes and pathophysiology of Chiari-I malformation (CM-I), definitive surgical treatment remains unresolved. Various techniques have been propounded over the years, but there is no general consensus on the most appropriate surgical management for this condition.

Aim: To compare patients related surgical results of Foramen Magnum Decompression with and without lax Duraplasty in Chiari Malformation Type-I with syringomyelia.

Settings and Design: This is a patient related prospective surgical outcome study conducted durong the period of four years from 2013 to 2017 in Stanley medical college, chennai.

Materials and Methods: Thirty five cases of CM-I with Syrinx were included. There were 12 patients (34.3\%) in the non-duraplasty Group-A and 23 patients (66.7\%) in the Lax duraplasty Group-B. The rate of patient clinical improvement in the form of preoperative and postoperative VAS pain score and nurick's score, reduction of postoperative Syrinx size, amount of tonsillar herniation, preoperative symptom duration and postoperative improvement, complications and reoperation rates were analysed for a minimum follow up period of one year.

Results: The rate of clinical improvement was significantly higher with Lax duraplasty Group-B (94.6\%) than Group-A (15.4\% with significant $p<0.05$. The rate of postoperative syrinx regression was significantly higher in the duraplasty Group-B (94.6\%) than in the non-duraplasty Group-A (15.4\%). No case in the duraplasty Group-B needed a reoperation compared with five cases in the non-duraplasty Group-A.

Conclusion: FMD with Lax Duraplasty(Group-B) is superior to stand alone FMD(Group-A)in CM-I associated with Syrinx with the expense of a slightly higher procedure related complication rate.

Keywords: Chiari Malformstion, Lax duroplasty, Syrinx, Tonsillar Herniation.
\end{abstract}

\section{Introduction}

There are six types of Chiari malformations are described in the literature. Chiari malformation type $1(\mathrm{CM}-1)$ is presented with the downward displacement of the cerebellar tonsils and the medial portions of the inferior cerebellar lobules through the foramen magnum into the upper cervical spinal canal. This causes out flow obstruction of cerebral spinal fluid (CSF) at the level of the foramen magnum, and thus changes the CSF hydro dynamics, causing syringomyelia (SM) or syrinx. Syringomyelia is defined as 
longitudinal cystic cavity in the central canal of the spinal cord ${ }^{[1,2]}$. Syrinx is commonly associated with $90 \%$ case of CM- 1 . The success rate of surgical decompression ranges from $45 \%-87 \%$ in various studies. Clinical presentation is commonly with brainstem compression, myelopathy secondary to syrinx formation. There is no ideal optimal surgical modality for the treatment of Chiari-I so for. Among the various surgical methods like foramen magnum decompression (FMD) with and without lax duraplasty, syrigostomy, syringopleural (SP) shunt, plugging of obex, syringosubarachnoid shunt and fourth ventriculosubarachnoid shunt procedures are advocated by various authors. Some authors recommend only FMD is sufficient ${ }^{[5-7]}$. Few authors advocate duraplasty or some additional techniques like various shunt procedures ${ }^{[1,8,9]}$. Present study is undertaken to compare the surgical results of FMD with and without lax duraplasty in CM-1 associated with Syrinx.

\section{Materials and Methods}

Thirty five cases were enrolled for this study during the period of four years from 2013 to 2017 with informed consent. Two surgeons were involved in this study. One surgeon who believes in the stand alone Foramen magnum decompression procedure cases are categorised as Group-A (12 CASES). The other surgeon who prefers the FMD with lax duroplasty categorised as Group-B (23 cases). All patients with progressive neurological deficit and image evidence of syrinx cases are included in this study. Other types of Chiari malformation cases, craniovertebral anomaly cases, additional shunt procedure done cases are excluded from this study.

Patient in prone position, head in flexion with minimum two finger breadth distance from anterior chest wall and lower jaw, head fixed in May field three pins head holder, midline incision marked from external occipital protuberance to C4spinous process level, after infiltrating the incision line with adrenaline saline with local anaesthetics like lignocaine and bupivacaine mixture, sub occipital cranium exposed via avascular plane through ligamentumnuchae. Foramen magnum decompression done with $3 \mathrm{~cm}$ height vertically and $4 \mathrm{~cm}$ wide horizontally. $\mathrm{C} 1$ laminectomy done with atleast $2 \mathrm{~cm}$ width in the mid portion ${ }^{[1,10-12]}$. The non-duraplasty Group-A (only FMD with no manipulation to the dura mater) consisted of 12 patients and the lax duraplasty Group-B (FMD and laxduraplasty using a Fascia Lata autograft from the ipsilateral thigh and fixed in watertight manner and additional reinforcement done with tissue glue (Tisseal)) consisted of 23 patients. All patients related parameters are recorded preoperatively and post operatively at first day, one week, during discharge, one, three, six, twelve months for clinical improvement and imaging study.

\section{Results}

Totally there are thirty five patients. In Group-A (males-8, females-4), In Group-B (males-11, females-12) as shown in bar chart-1 and pie chart2. The common clinical presentation is nuchal and occipital head ache, numbness and dissociative sensory loss, other clinical presentations are depicted in bar chart-3.

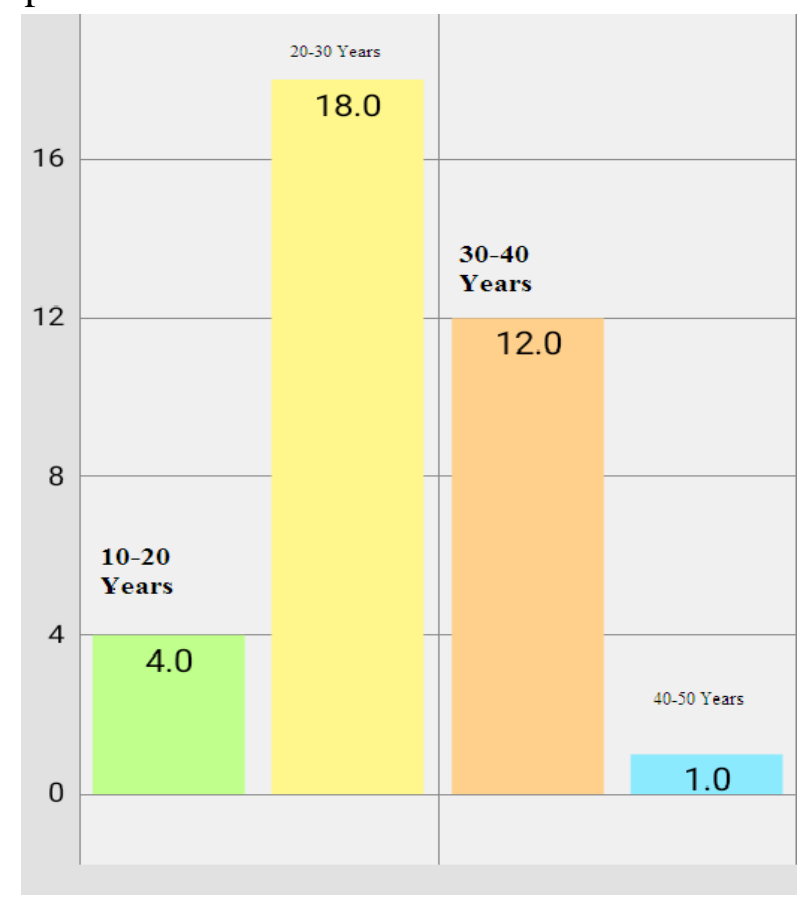

Chart-1 Shows patients age distribution 


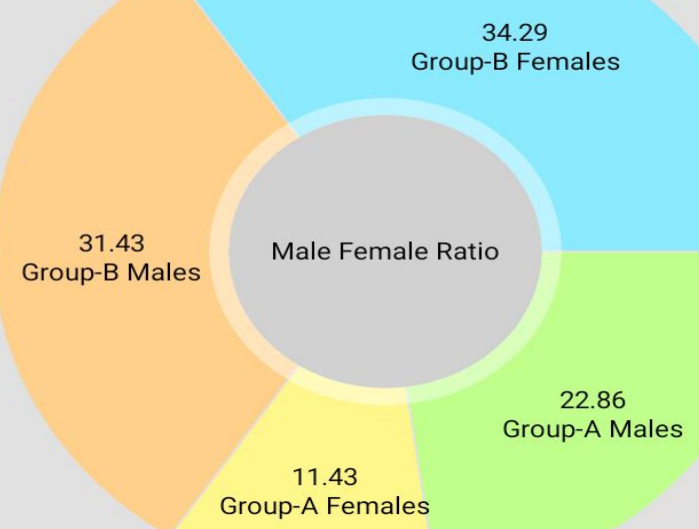

Chart-2 shows sex distribution of the study group

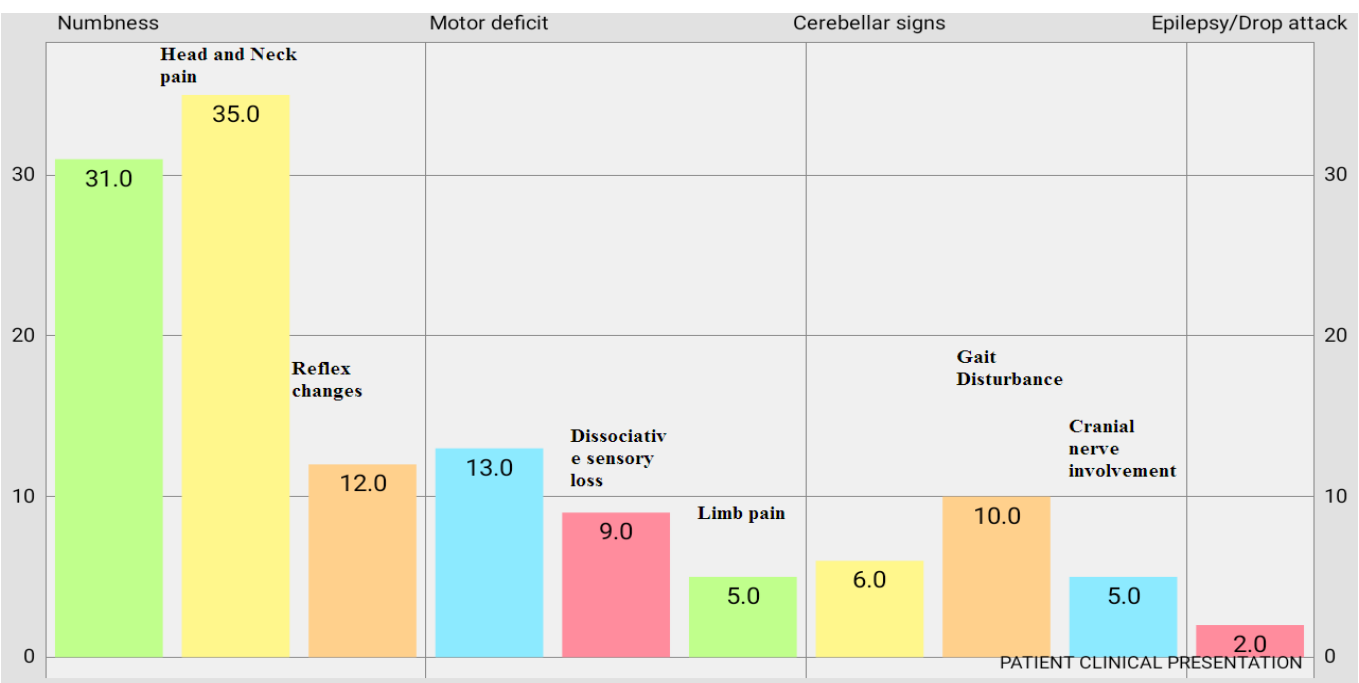

Chart-3 shows the patients clinical presentation spectrum

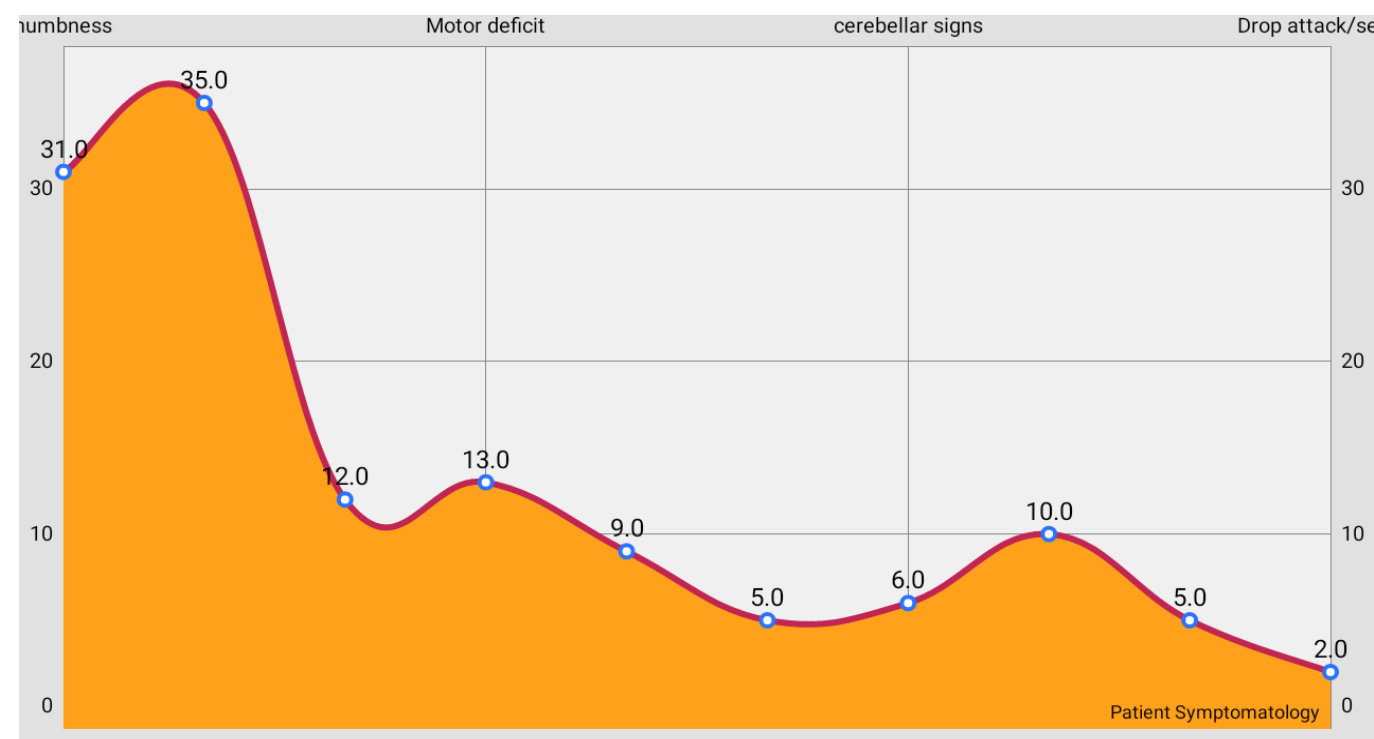

Chart.4 shows the common presentation of CHIARI-1 Malformation 


\section{JMSCR Vol||07||Issue||02||Page 985-991||February}

Table.1 shows the comparative study results between two Groups

\begin{tabular}{|l|c|c|c|}
\hline S.No & Parameters & Group-A(FMD) & Group-B (FMD+Lax Duraplasty) \\
\hline 1 & Clinical improvement & Late & Early \\
\hline 2 & Surgery time & $<1$ Hour & Present \\
\hline 3 & $\begin{array}{c}\text { Donar site morbidity with Fascia } \\
\text { havesting site }\end{array}$ & No & Possible \\
\hline 4 & CSF leak & No & Possible \\
\hline 5 & Pseudo meingocoele & No & Possible \\
\hline 6 & Meningitis & Inadequate, & Possible \\
\hline 7 & Decompression & Not possible & Needed \\
\hline 8 & Tonsillar removal & Not needed & Needed \\
\hline 9 & Tisseal application & Not needed & Must \\
\hline 10 & Ligation of occipital venous sinus & - & Often needed \\
\hline 11 & Water tight dural closure & Not Needed & Needs delicate work \\
\hline 12 & Additional Blood transfusions & Simple & $\begin{array}{c}\text { Direct restoration of CSF } \\
\text { hydrodynamics }\end{array}$ \\
\hline 13 & Learning curve & $\begin{array}{c}\text { Indirect decompression and to wait } \\
\text { for dura to expand by natural means }\end{array}$ & Effectiveness \\
\hline 14 & & &
\end{tabular}

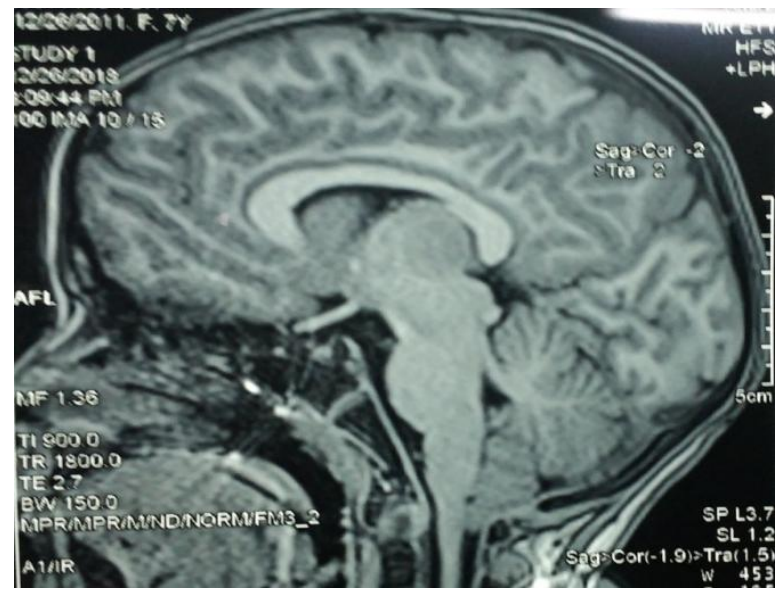

Figure 1 pre op MRI Image shows the peg like elongation of cerebellar tonsil $7 \mathrm{~mm}$ size in to the upper spinal canal

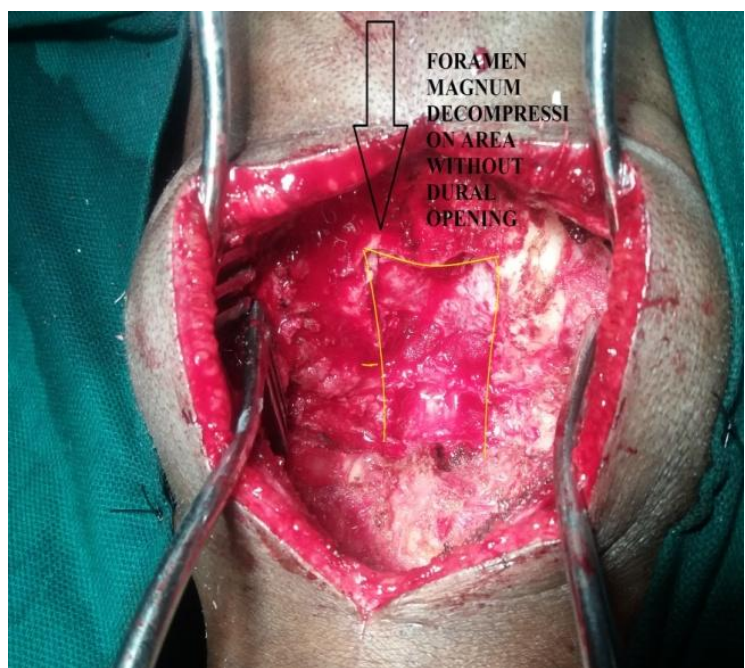

Figure 2 Showing the stand alone Foramen Magnum Decompression

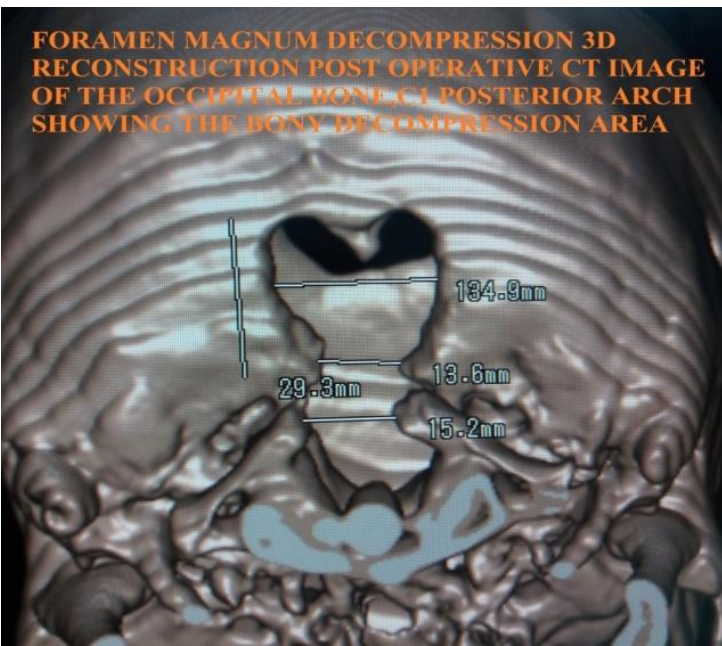

Figure 3 Shows the post operative CT image of FMD procedure

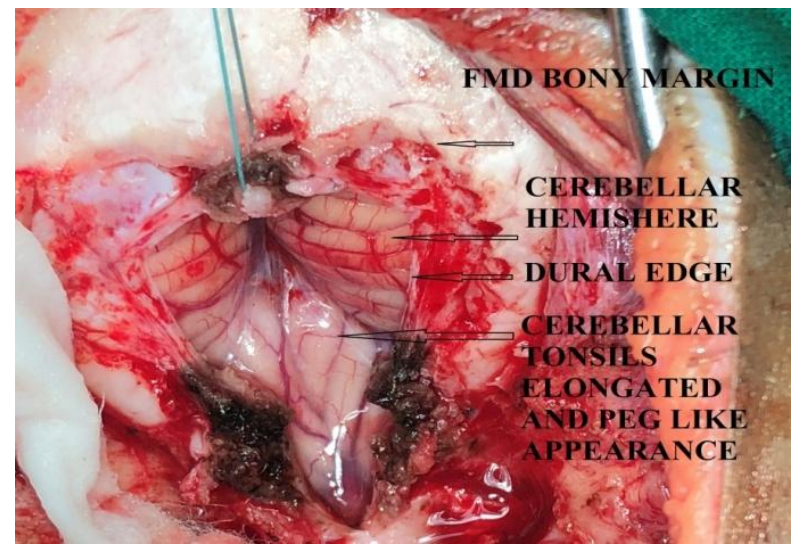

Figure 4 shows the Intra op picture of FMD+DURAPLASTY Procedure 


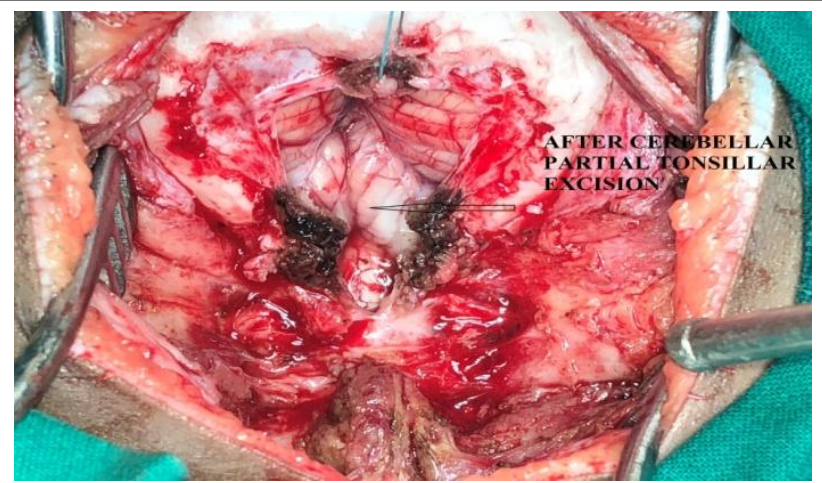

Figure 5 shows the cerebellar tonsillar excision

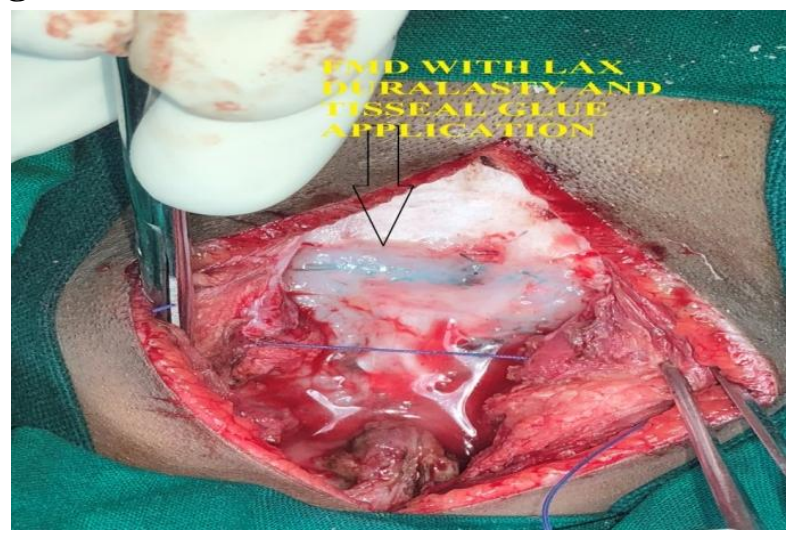

Figure 6 shows the Lax duraplasty step

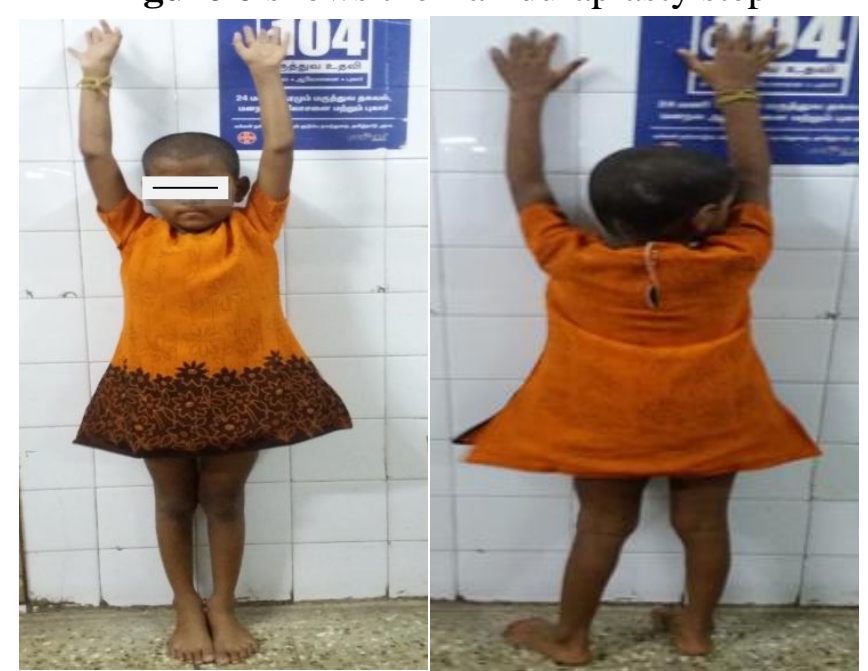

Figure 7 shows the post op status without deficit

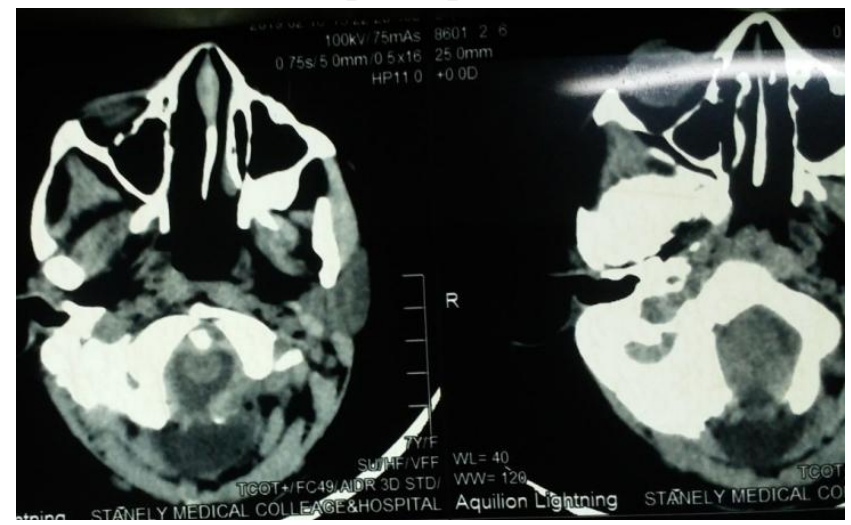

Figure 8 Post op CT Image of FMD+LAX DURAPLASTY

\section{Discussion}

Chiari malformation type-I occurs due to congenital or acquired aetiologies. It is commonly due to the cerebellar tonsils descends and peg into the cervical spinal canal like piston and alters the CSF hudrodynamics and leads to syrinx formation $^{[2,4,14,16]}$. It is associated with syrinx in $30 \%-70 \%$ of cases $^{[5,15]}$. In other words, $90 \%$ of syrinx cases are associated with Chiari-1.Signs and symptoms are directly due to brainstem compression at the level of foramen magnum or syringomyelia $^{[2,4]}$. Head and neck pain is the most common presentation ${ }^{[4,12]}$. Motor and sensory disturbances, long tract signs, cerebellar signs, lower cranial nerve disturbances, nystagmus, hyperreflexia, and ataxia are other neurological findings associated with Chiari-1malformation [2,5,17]. Clinical and radiological evidence are needed to diagnose this entity ${ }^{[11]}$. MRI is the gold standard diagnostic technic ${ }^{[2,18]}$. Cine flow MRI studies are advocated in decision making of the ideal surgical procedure ${ }^{[14,16,19,20]}$. CT Scan is must to understand the bone anatomy and surgical planning ${ }^{[11,17,21]}$. The optimal and ideal surgical procedure of choice is established based on the clinical findings ${ }^{[22]}$. Some authors states that FMD alone is sufficient ${ }^{[6,7,23]}$, whereas others suggest duraplasty or different shunt procedures ${ }^{[1,4,8,9]}$. Erdogan et al. ${ }^{[1]}$ reported that the symptoms and signs resolved in $83 \%$ of their patients following FMD without duraplasty, but syrinx regression was only $28 \%$. Syrinx size reduction reported higher according to Ramnarayan et al with duropllasty ${ }^{[2]}$. Romero and Pereira et al ${ }^{[9]}$ reported that duraplasty is effective in Chiari-1 cases with spinal cord syrinx. Present study, the rate of postoperative syrinx regression was significantly higher in the duraplasty Group-B (94.6\%) than the non-duraplasty group $(5.4 \%, p<0.05)$. The syrinx size remained unchanged in $15.4 \%$ of duraplasty patients and $94.6 \%$ of non-duraplasty patients. In this study the clinical improvement is strongly associated with disappearance or reduction in size of the cervical cord syrinx. These results show 
that FMD with laxduraplasty is superior to FMD alone.

\section{Conclusion}

According to the results of the present study, the Foramen Magnum Decompression should be supplemented with lax duraplasty in the surgical management of Chiari-I malformation. Even though the procedure is seem to be associated with more difficulty, needs experience, time consuming, and dural autograft donor site morbidity than simple FMD, it is the complete procedure and patients friendly procedure. Simple FMD is surgeons friendly procedure, but there is no direct and immediate decompression effect according to our study. Small sample size, single centre study and non randomisation of study population are few draw backs of this study.

Conflict of Interest: None to declare

\section{References}

1. Erdogan E, Cansever T, Secer HI, et al. The evaluation of surgical treatment options in the Chiari Mal- formation Type I. Turk Neurosurg 2010;20:303-13.

2. Ramnarayan R, Praharaj MS, Jayakumar PN. Chiari1 malformations: an Indian hospital experience. Sin- gapore Med J 2008;49:1029-34.

3. Dyste GN, Menezes AH, VanGilder JC. Symptomatic Chiari malformations: an analysis of presentation, management, and long-term outcome. J Neurosurg 1989;71:159-68.

4. Rehman L, Akbar H, Bokhari I, Babar AK, AS MH, Arain SH. Posterior fossa decompression with dura- plasty in Chiari1 malformations. J Coll Physicians Surg Pak 2015;25:254-8.

5. Goel A, Desai K. Surger y for syringomyelia: an analysis based on 163 surgical cases. ActaNeurochir (Wien) 2000;142:293-301.
6. Navarro R, Olavarria G, Seshadri R, Gonzales-Porti- llo G, McLone DG, Tomita T. Surgical results of pos- terior fossa decompression for patients with Chiari I malformation. Childs NervSyst 2004;20:349-56.

7. Padget DH. Development of so-called dysraphism: with embryologic evidence of clinical Arnold-Chiari and Dandy-Walker malformations. Johns Hopkins Med J 1972;130:127-65.

8. Munshi I, Frim D, Stine-Reyes R, Weir BK, Hek- matpanah J, Brown F. Effects of posterior fossa de- compression with and without duraplasty on Chiarimalformation-associated hydromyelia. Neurosurgery 2000;46:1384-9.

9. Romero FR, Pereira CA. Suboccipitalcraniectomy with or without duraplasty: what is the best choice in patients with Chiari type 1 malformation? ArqNeuropsiquiatr 2010;68:623-6.

10. da Silva JA, dos Santos AA Jr, Melo LR, de Araujo AF, Regueira GP. Posterior fossa decompression with tonsillectomy in 104 cases of basilar impression, Chi- ari malformation and/or syringomyelia. ArqNeurop- siquiatr 2011;69:817-23.

11. Taricco MA, Melo LR. Retrospective study of pa- tients with Chiari: malformation submitted to surgi- cal treatment. Arq Neuropsiquiatr 2008;66:184-8.

12. Zhou DB, Zhao JZ, Zhang D, Zhao YL. Suboccipital bony decompression combined with removal of the dural band as treatment for Chiari I malformation. Chin Med J (Engl) 2004;117:1274-7.

13. Yilmaz A, Kanat A, Musluman AM, et al. When is duraplasty required in the surgical treatment of Chi- ari malformation type I based on tonsillar descend- ing grading scale? World Neurosurg 2011;75:307-13.

14. Cahan LD, Bentson JR. Considerations in the diag- nosis and treatment of 
syringomyelia and the Chiari malformation. J Neurosurg 1982;57:24-31.

15. Arruda JA, Costa CM, Tella Jr OI. Results of the treatment of syringomyelia associated with Chiari malformation: analysis of 60 cases. ArqNeurop- siquiatr 2004;62:237-44.

16. McGirt MJ, Nimjee SM, Floyd J, Bulsara KR, George TM. Correlation of cerebrospinal fluid flow dynamics and headache in Chiari I malformation. Neurosur- gery 2005;56:716-21.

17. Klekamp J. Surgical treatment of Chiari I malforma- tion: analysis of intraoperative findings, complica- tions, and outcome for 371 foramen magnum de- compressions. Neurosurgery 2012;71:365-80.

18. Fujii K, Natori Y, Nakagaki H, Fukui M. Management of syringomyelia associated with Chiari malforma- tion: comparative study of syrinx size and symptoms by magnetic resonance imaging. SurgNeurol 1991;36:281-5.

19. Koc K, Anik Y, Anik I, Cabuk B, Ceylan S. Chiari-1 malformation with syringomyelia: correlation of phasecontrast cine MR imaging and outcome. Turk Neurosurg 2007; 17:183-92.

20. Panigrahi M, Reddy BP, Reddy AK, Reddy JJ. CSFflow study in Chiari I malformation. Childs NervSyst 2004;20:336-40.

21. Matsumoto T, Symon L. Surgical management of syringomyelia: current results. SurgNeurol 1989;32:258-65.

22. Bindal AK, Dunsker SB, Tew JM Jr. Chiari I malfor- mation: classification and management. Neurosur- gery 1995;37:1069-74.

23. Batzdorf U. Chiari I malformation with syringomy- elia: evaluation of surgical therapy by magnetic resonance imaging. $\mathbf{J}$ Neurosurg 1988;68:726-30. 